\title{
EXCAVACIÓN ARQUEOLÓGICA EN EL DOLMEN DE LA FUENTE DEL CORCHO (BELMEZ, CóRdobA)
}

\author{
Beatriz Gavilán Ceballos \\ YesSiCA RodRÍGUEZ EsPINOSA \\ Rafael Maura Mijares \\ Universidad de Huelva
}

Recibido: $12 / 12 / 2012$

Revisado: 18/01/2013
Aceptado: 24/01/2013

Publicado: 17/06/2013

\section{REsUmen}

Presentamos en este trabajo los resultados derivados de la excavación arqueológica efectuada en el Dolmen de la Fuente del Corcho, en Belmez (Córdoba). Aunque esta sepultura fue saqueada a finales del siglo pasado, ha proporcionado interesantes datos, sobre todo referentes a la decoración de algunos de sus ortostatos.

\section{Palabras Clave} tico.

\section{ABSTRAC}

We present in this work the results derivatives of the archaeological excavation issued within the Dolmen de la Fuente del Corcho, in Belmez (Córdoba). Although this burial was sacked to late last century, has provided interesting data, especially referents to decoration of some of its orthostats.

\section{KEYWORDS}

Barrow, Trousseau, Orthostats, Bowls, Chalcolithic. 


\section{INTRODUCCIÓN}

\section{SITUACIÓN}

El Dolmen de la Fuente del Corcho se localiza en las coordenadas geográficas $38^{\circ} 13$ ' $51^{\prime}$ y y $1^{\circ} 31^{\prime} 02$ ", de la Hoja 879 (Fuente Obejuna) del M.T.N. E. 1: 50.000. Se accede hasta él por la carretera comarcal de Belmez al Entredicho, a unos $15 \mathrm{~m}$ de distancia del poste kilométrico 3,600 (fig.1) y a unos $2 \mathrm{~km}$ del arroyo Fresnedoso, tributario del Guadiato. Fue construido sobre una ligera elevación de unos $\mathbf{5 2 3}$ m.s/n.m., extendiéndose hacia el norte y el este una zona llana que dota a esta estructura megalítica de amplia visibilidad en dichas direcciones, divisándose varios de los poblados calcolíticos que jalonan

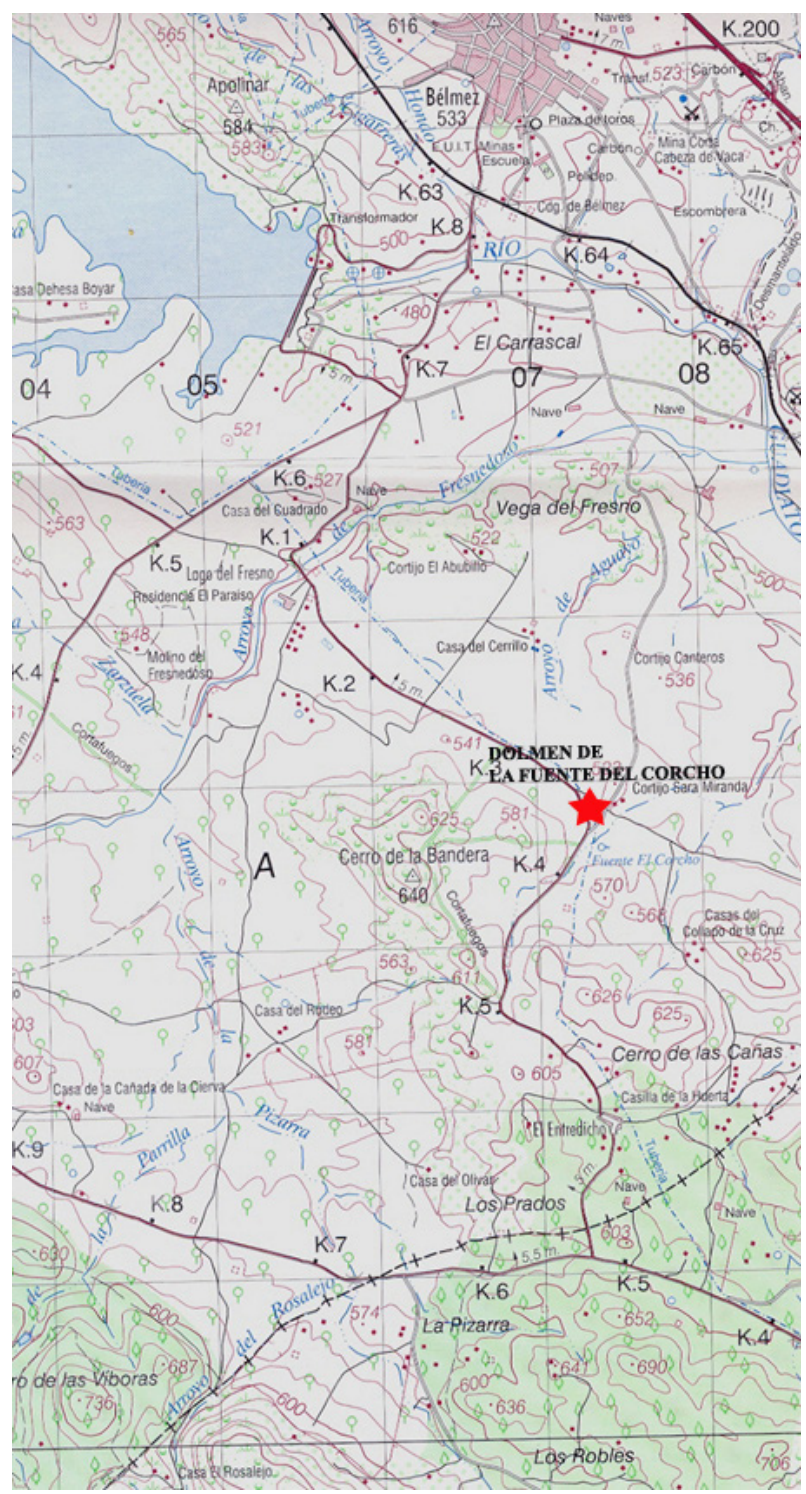

Fig. 1. Situación del Dolmen de la Fuente del Corcho. el Alto Valle del Guadiato en su margen izquierda, como El Peñón (Peñarroya-Pueblonuevo), El Castillo de Belmez y Sierra Palacios I, a cuya necrópolis pertenece este dolmen (figs. 2 y 3) (Gavilán, 20032004). Hasta el momento, y junto con el Dolmen de las Casas de Don Pedro (Gavilán, 2003-2004; Gavilán y Vera, 2005), son los únicos sepulcros megalíticos pertenecientes a dicha necrópolis que han sido excavados, aunque otros han sido objeto de remociones no autorizadas.

\section{CAUSAS DE LA INTERVENCIÓN.}

Los trabajos de excavación, realizados entre julio y agosto de 2005, fueron motivados por las actividades clandestinas cometidas en 1988, que afectaron al interior y al exterior de la cámara -según pudimos comprobar en los primeros días de excavación-, así como por la destrucción de parte del lado norte del túmulo que cubría la estructura megalítica, arrasado por una retroexcavadora que ocasionó el desplazamiento de varios bloques de su lugar original, entre ellos los que formaban el lateral norte de la cámara funeraria que, carente de relleno, bascularon hacia el interior (fig. 4 B y C). Además, varias piedras sueltas, igualmente desplazadas y de gran tamaño, se encontraban sobre la zona del corredor.

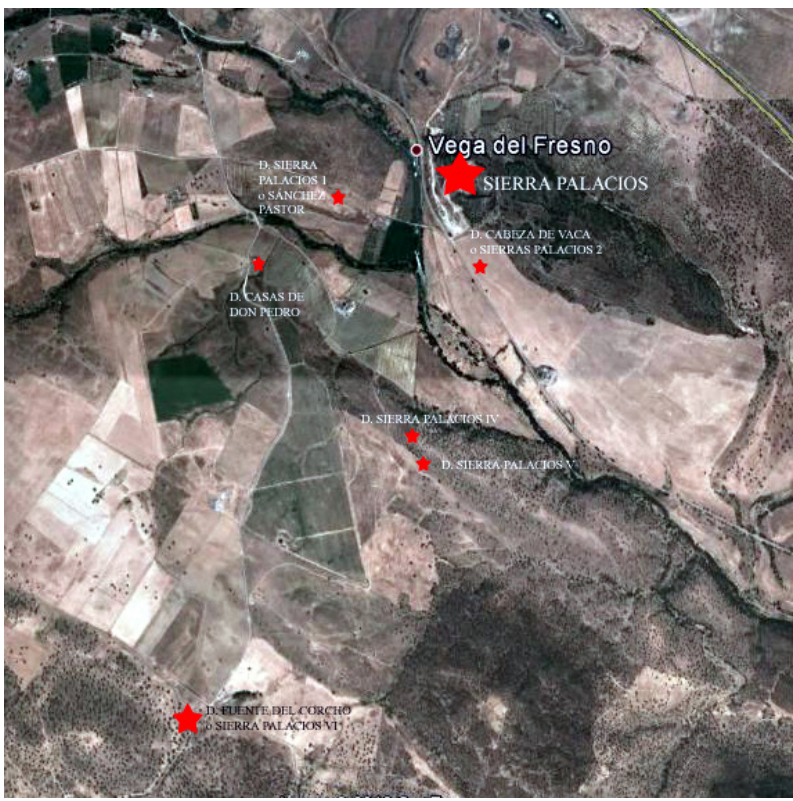

Fig. 2. Situación del poblado de Sierra Palacios I, el Dolmen de la Fuente del Corcho y otros sepulcros de la necrópolis dolménica del asentamiento. 


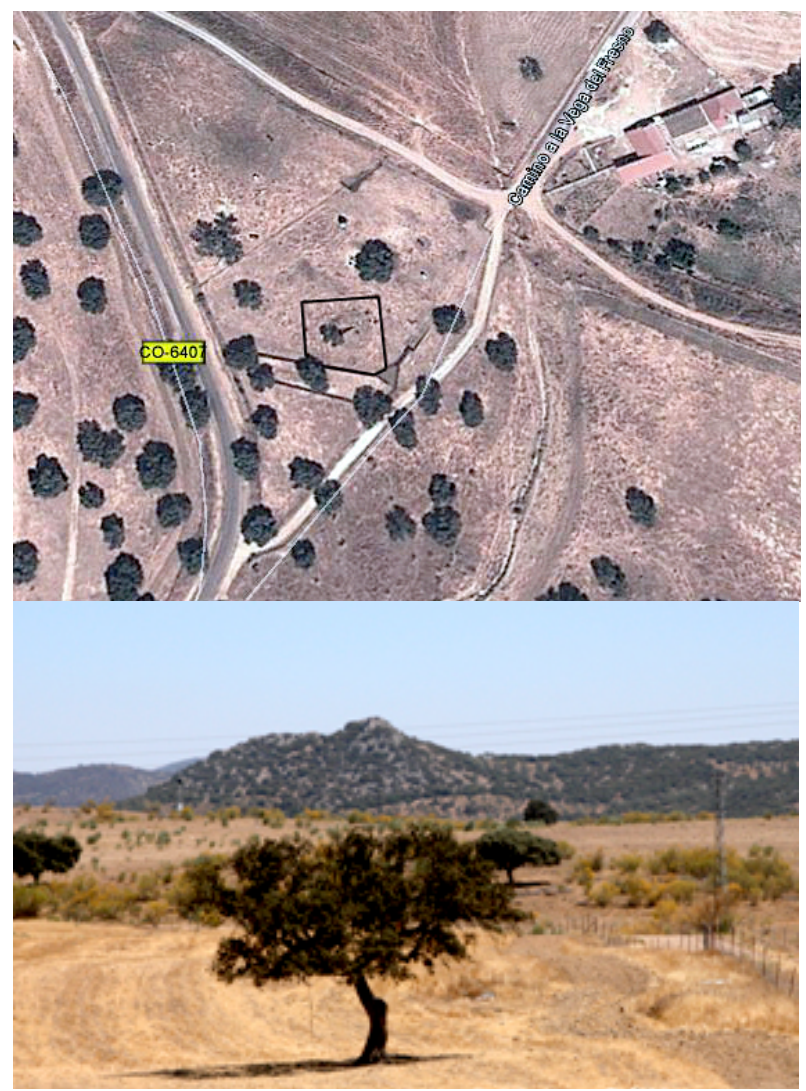

Fig. 3. Dolmen de la Fuente del Corcho y Sierra Palacios desde el dolmen.

\section{DesarRollo DE LA EXCAVACióN}

Tras la medición del túmulo - de 19’3 m, de este a oeste, y 17 ' $1 \mathrm{~m}$, de norte a sur- procedimos a trazar una gran cuadrícula, de 20x18 ms, que comprendía toda la masa tumular, subdividiéndola en dos en dirección este-oeste: $\mathrm{A}$, de $8 \mathrm{~m}$ de ancho, y B, de 10 $\mathrm{m}$, medidas que responden al eje de orientación de la cámara funeraria; y en 10 de norte a sur, de $3 \mathrm{~m}$ de anchura las dos primeras, al oeste, y de $2 \mathrm{~m}$. las restantes (fig. 5).

A continuación retiramos las piedras sueltas de gran tamaño que habían sido desplazadas por la máquina hacia la zona central norte del túmulo, (fig. 4 B y C), dejándose entrever una cámara aún de forma indeterminada y con bloques desplazados en su interior, sin que se apreciasen los elementos constructivos del corredor. Seguidamente comenzamos la excavación, interviniendo simultáneamente en el túmulo y la cámara, y finalmente en el corredor.

Al tratarse de una sepultura megalítica bastante afectada por remociones clandestinas y por la extracción de tierra de parte del túmulo, fuimos rebajando este sector por alzadas artificiales, que estable-

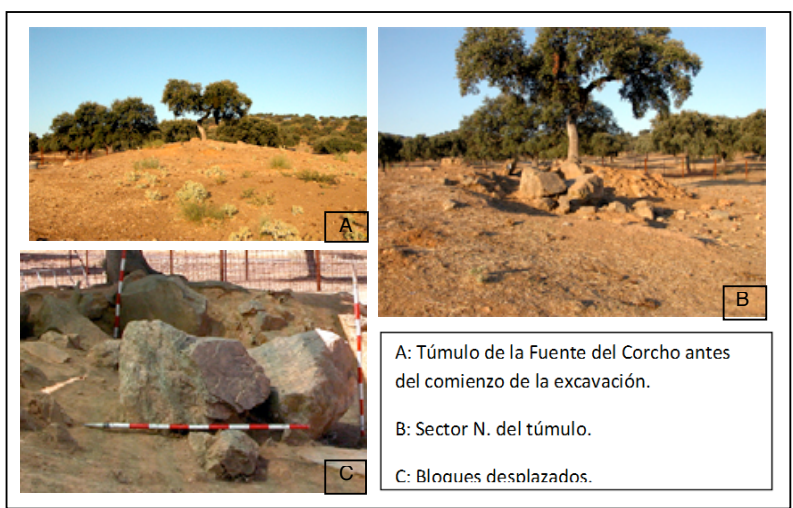

Fig. 4. Túmulo de la Fuente del Corcho y destrozos ocasionados por una retroexcavadora.

cimos en $10 \mathrm{~cm}$. En el caso de la cámara era de todo punto imposible plantear al principio una excavación por niveles naturales o artificiales, ya que estaba colmatada por tierra revuelta y por los bloques que habían basculado hacia el interior. Finalmente, el corredor, que tras la intervención en la cámara se vislumbraba como el único espacio intacto, fue excavado por niveles naturales, aunque estableciendo alzadas artificiales dentro de éstos porque contábamos con una visión frontal de la estratigrafía, que quedó al descubierto después de retirar los bloques y la tierra suelta del interior de la cámara.

La tierra fue cribada en seco, desistiendo del empleo de criba de agua ante la ausencia de restos de carbones y, en general, cualquier tipo de evidencia de combustión que permitiese la posible recuperación de macro y microrrestos vegetales.

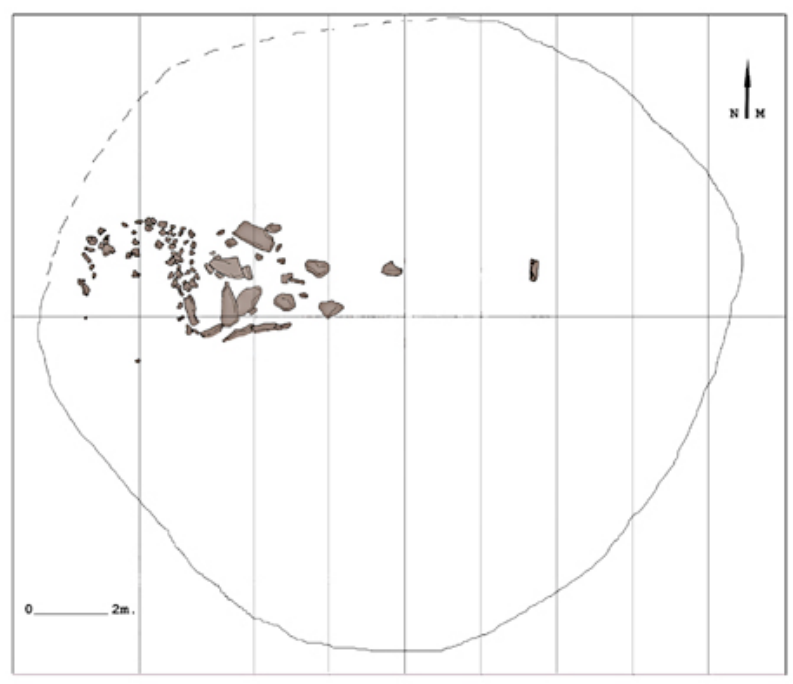

Fig. 5: Estado del Dolmen de la Fuente del Corcho al comienzo de la excavación. 


\section{EXCAVACIÓN DEL TÚMULO.}

La retirada de la tierra suelta del túmulo dejó a la luz una capa de piedras de mediano tamaño que afloraba en los lados noroeste y norte, aumentando en cantidad y volumen hacia la base del mismo, pero sin llegar a formar un verdadero anillo perimetral (fig. 6). Ante esto, excavamos una alzada de unos $8 \mathrm{~cm}$ de espesor, comprobando que la capa de piedras, embutidas en una tierra de color beigeamarillento, se extendía hacia el resto del túmulo. En su cota más elevada, tras retirar una primera capa de tierra y descarnar las piedras, apareció un cuenco de cerámica casi completo y varios fragmentos de otros, uno de ellos de cerámica campaniforme (fig. 7). Estos ítems no estaban asociados a restos óseos humanos que se hayan conservado, pero evidencian la continuidad en el funcionamiento de esta estructura megalítica con el cambio de ritual a comienzos del II milenio. Aparte de este ajuar, en la tierra del túmulo localizamos, en la zona este, escasos materiales prehistóricos y restos actuales, que aparecían en diferentes sectores del mismo entre la tierra de descarnado de las piedras, encontrándose varios fragmentos de vidrio a escasos $\mathrm{cm}$ del cuenco más arriba citado. La remoción que evidencian estos restos puede ser una de las causas de la ausencia de restos óseos humanos asociados al ajuar prehistórico del túmulo.

En el lado sur, en contacto con los bloques de la cámara, practicamos una cata con la intención de documentar las zanjas de inserción de estos ortostatos que estaban in situ, poniéndose de manifiesto el intenso expolio que se había efectuado en este dolmen, ya que localizamos una gran cantidad de

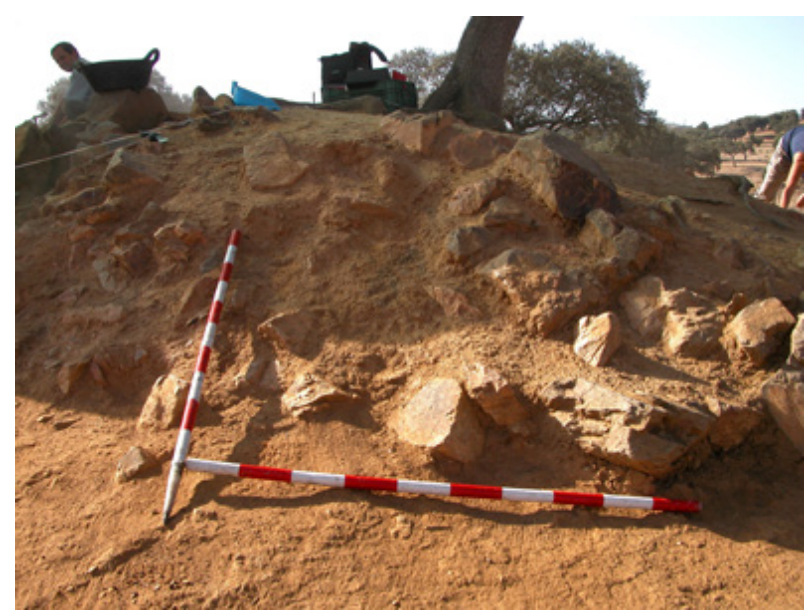

basura que alcanzaba parte de la cámara funeraria al haberse deslizado por los intersticios existentes entre los ortostatos. Retirados los desechos, y tras una primera capa de escasos cm de potencia, comenzó a aparecer una tierra de color marrón-rojizo (que después excavaríamos en parte del corredor, Nivel 2) y algunas piedras de mediano tamaño hasta alcanzar una profundidad de $-75 \mathrm{~cm}$, cota en la que apareció una capa de piedras, igualmente de tamaño medio (fig. 8), que cubría toda la extensión de la cata. Esta capa posiblemente circundaba parte de la estructura funeraria ya que en el lado norte, arrasado en gran medida, se apreciaban piedras de similares dimensiones y a la misma cota en la zona intacta.

\section{EXCAVACIÓN DE LA CÁMARA.}

La denominación de este sector del espacio funerario obedece a que al iniciarse los trabajos no era posible determinar la forma completa de la estructura megalítica, que parecía corresponder a un característico dolmen de cámara y corredor diferenciados.

Comenzamos retirando la tierra revuelta del interior de la cámara, donde se encontraban los bloques del lado norte, empujados por la retroexcavadora. Entre éstos y los del lado sur, in situ, localizamos restos de basura que se extendía hacia los amplios intersticios existentes entre los bloques, circunstancia que motivó la excavación, ya referida, de una franja de tierra del túmulo a partir de la cara externa de los bloques de dicho lateral, detectándose la zanja abierta por los clandestinos (fig. 9) y gran cantidad de basura.

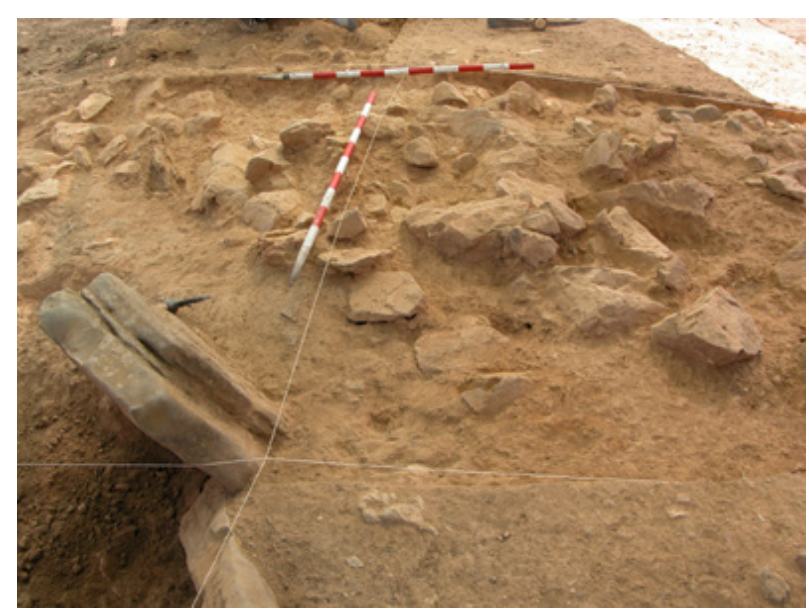

Fig. 6. Piedras de mediano tamaño que forman parte de la costra que cubría el túmulo. Sector norte y zona superior del túmulo. 

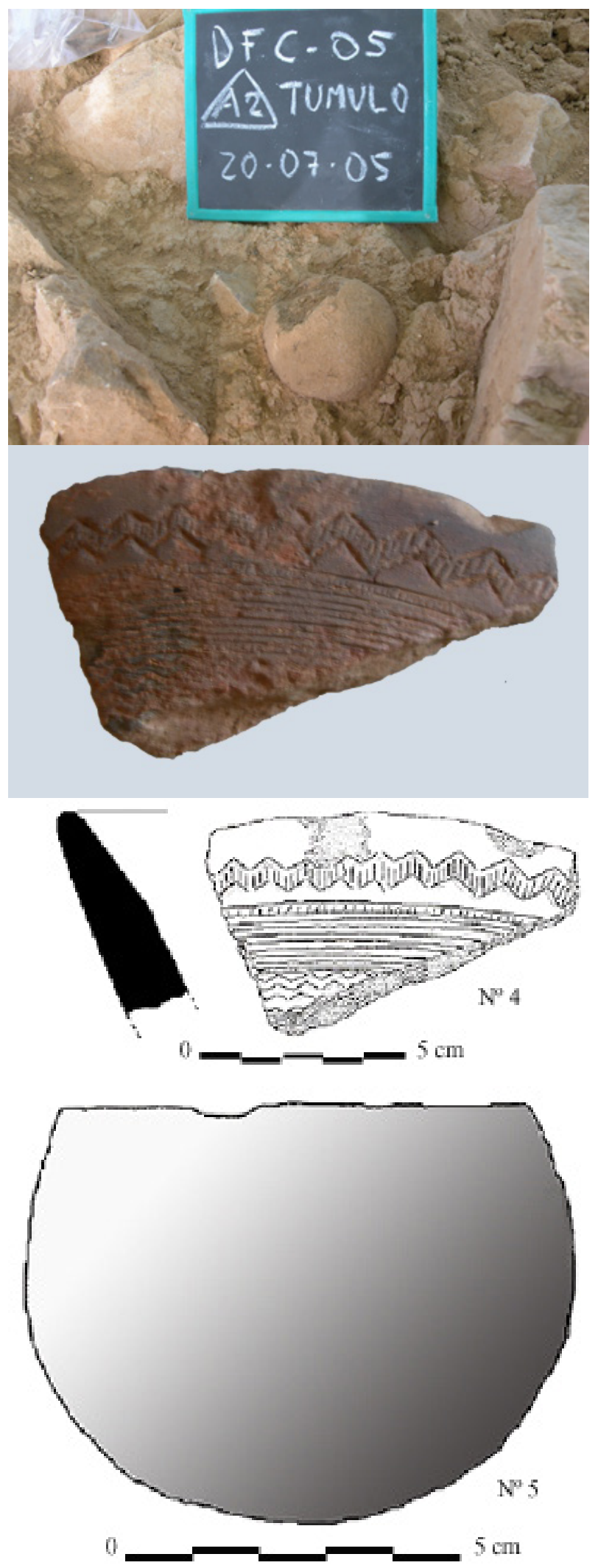

Fig. 7. Ajuar recuperado en el túmulo: fragmento de campaniforme y cuenco.

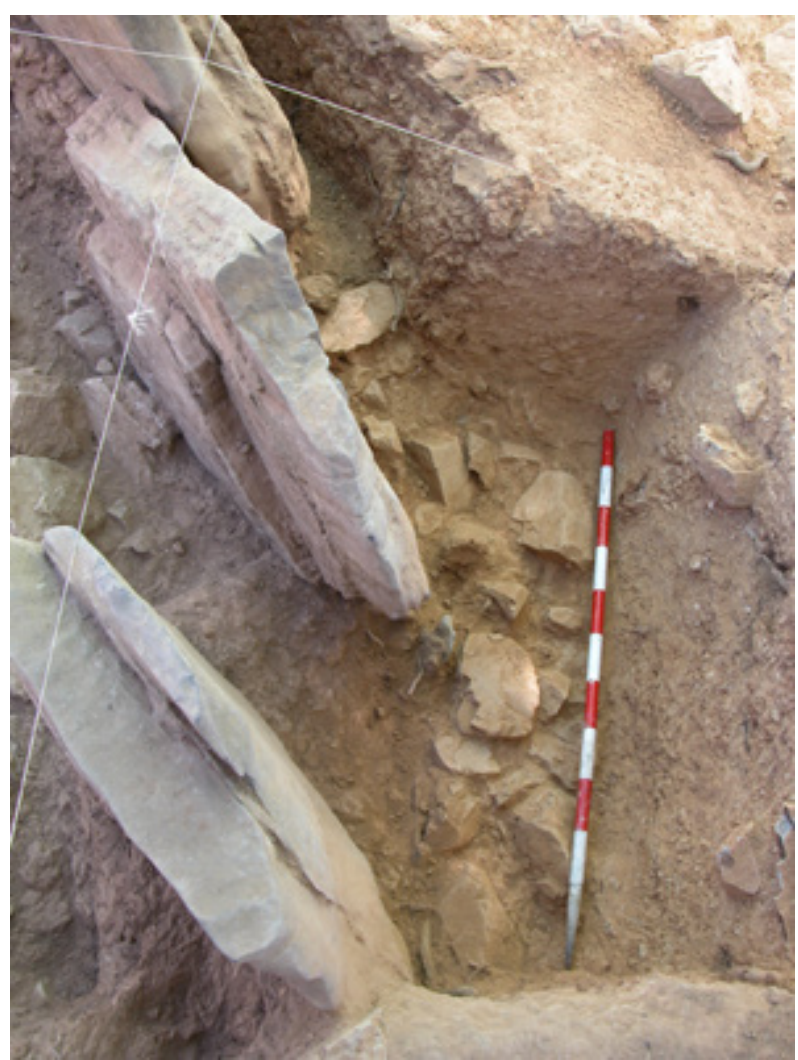

Fig. 8: capa de piedras que circundaba la cámara al exterior.

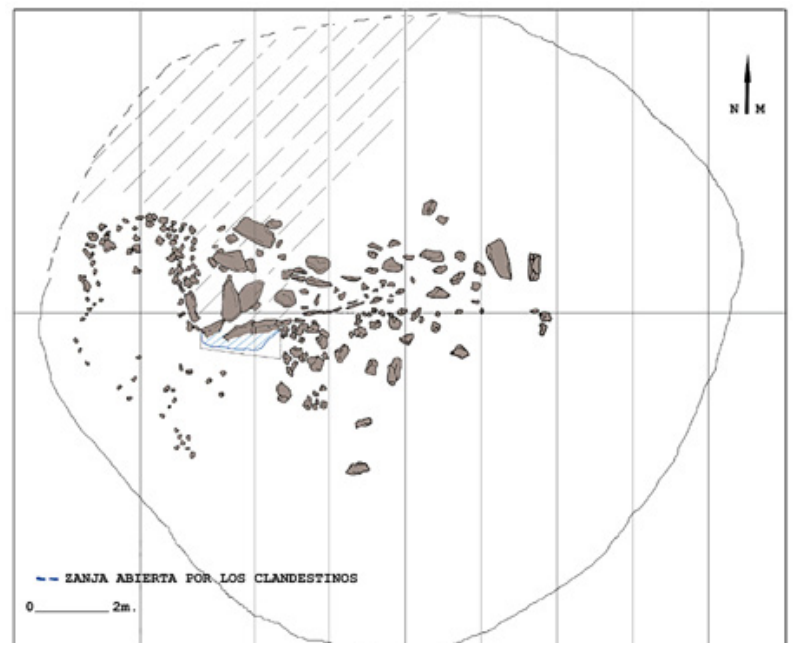

Fig. 9. Situación de la zanja abierta por los clandestinos. 


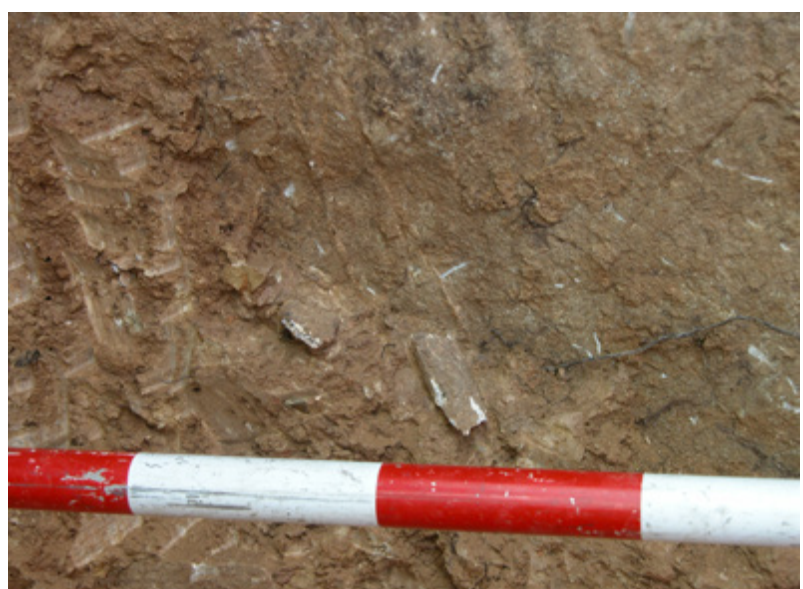

Fig. 10. Restos óseos del interior de la cámara.

Seguidamente pasamos a retirar los bloques del lateral norte, apreciándose que los clandestinos habían arrasado prácticamente la totalidad de la cámara, llegando hasta la base, en cuyo interior sólo pudimos documentar escasísimos restos del ajuar funerario: 2 puntas de flecha, 1 hacha y varios fragmentos de cerámica, como elementos más significativos, así como restos óseos reducidos a fragmentos y esquirlas no identificables (fig. 10), que se encontraban en el escaso sedimento intacto, adherido éste a los bloques del lado sur, casi en su base, tratándose de una tierra de color rojo que excavamos en el corredor como nivel 2 .

Algunos de los bloques del lado norte de la cámara ofrecían las huellas dejadas por la retroexcavadora, otros presentaban una serie de surcos, profundos y lineales, posiblemente debidos a los trabajos relacionados con la extracción de las lajas de piedra destinadas a formar esta estructura megalítica, y otro, grabados y cazoletas. Cuando se excavó el corredor pudimos comprobar que el segundo bloque de los conservados en este espacio funerario, y también en el lado norte, ofrecía igualmente cazoletas y grabados, que han sido objeto de una exhaustiva documentación (figs. 11-13).

Con la finalidad de documentar las zanjas de inserción de los bloques del lado norte de la cámara para poder determinar la forma de ésta, y plantear la posibilidad de restituirlos, rebajamos unos $15 \mathrm{~cm}$ de la base, formada por una tierra de color amarillento y totalmente estéril. Sin embargo dichas zanjas no resultaron apreciables al haberse rellenado con la misma tierra. Así, pues, centramos los trabajos en el corredor, que parecía intacto, simultaneando su excavación con el descarnado de las piedras del túmulo.

\section{EXCAVACIÓN DEL CORREDOR}

Con una potencia estratigráfica de poco más de $1 \mathrm{~m}$, se observaban 3 niveles (fig. 14):

Nivel 1: Tierra beige-amarillenta, arcillosa. Era la misma que formaba la primera capa del túmulo, alcanzando aquí una potencia de unos $40 \mathrm{~cm}$. Excavada una capa de unos 10-12 empezaron a aflorar los bloques que formaban el corredor, ligeramente orientado hacia el noreste. A partir del inicio de la cámara y final del corredor se disponían cuatro bloques al norte y otros tantos al sur, abarcando una longitud de unos 2'20 m, cuyas características, formales y líticas, eran semejantes a los de la cámara funeraria. En toda la potencia de este nivel aparecían en el interior del corredor piedras de mediano y pequeño tamaño, entre 25-35 y 10-12 cm de diámetro, respectivamente. Superada la citada longitud y hacia el noreste, se encontraban piedras de gran tamaño que, en esta fase de la excavación,
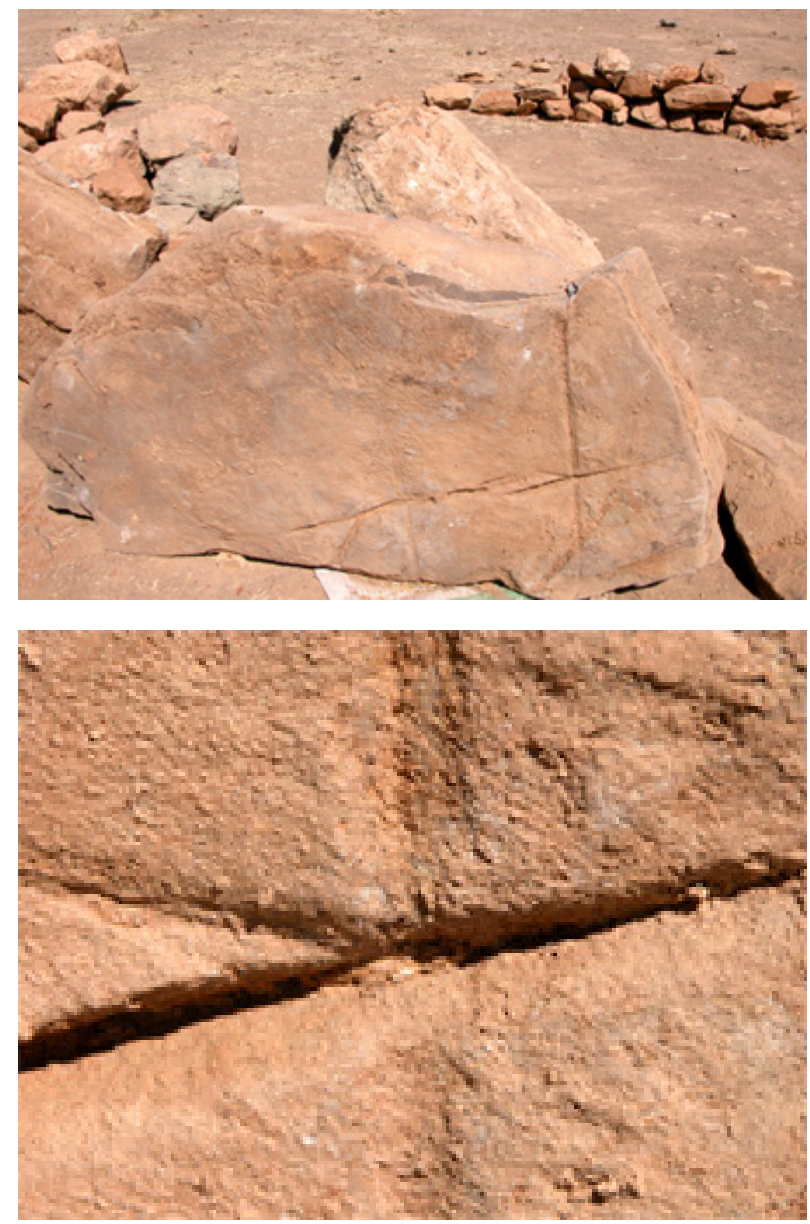

Fig. 11. Ortostato en el que se observan surcos profundos y lineales ocasionados por los trabajos de extracción de los bloques de piedra. 

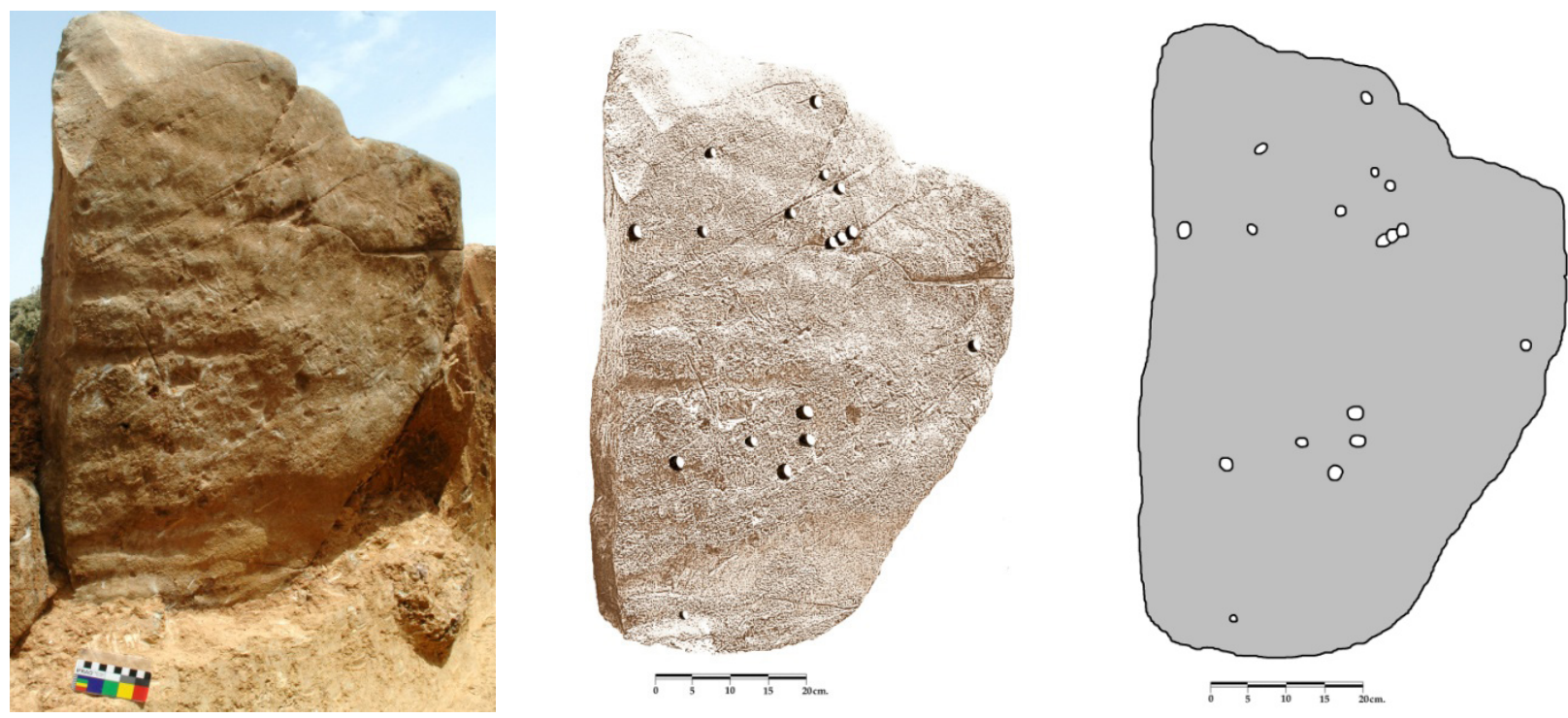

Fig. 12. Ortostato $\mathrm{n}^{\circ} 1$, del lado norte del corredor.

consideramos como pertenecientes al túmulo, aunque de mayores dimensiones, al concordar con ellas en el tipo de piedra elegido y por el hecho de haberse empleado en bruto, sin modificación. Este nivel resultó completamente estéril.

Nivel 2: Tierra roja, arcillosa y de rápida oxidación, de unos $60 \mathrm{~cm}$ de potencia. Adquiría una tonalidad más marrón en el tramo del corredor formado por las piedras semejantes a las de túmulo, diferencia que nos llevó a separar el sedimento de ambos tramos, empleando denominaciones distintas. Al igual que el nivel anterior, este contenía también bastantes piedras, aunque de menor tamaño, que aparecieron en los primeros $20-30 \mathrm{~cm}$ de potencia.

Este nivel proporcionó unos restos óseos en pésimo estado de conservación que se encontraban en el inicio de la primera parte del corredor, la conse- cutiva a la cámara, localizándose la mayoría al final de la segunda, y en ambos casos en los laterales del mismo, mientras que los fragmentos cerámicos estaban más próximos a la cámara e igualmente arrinconados en los laterales. Aunque este nivel era fértil, el escaso material que contenía estaba reducido a fragmentos, recuperándose, sobre todo, restos cerámicos, localizándose debajo de uno de ellos un resto óseo imposible de determinar por su reducido tamaño.

A lo largo de la excavación de este segundo nivel quedó patente que las piedras situadas en el sector más alejado del inicio de la cámara, que creíamos correspondientes al túmulo, formaban parte del corredor aunque eran virtualmente diferentes, en forma y material pétreo, a las del tramo en contacto con la cámara. Así, a partir del
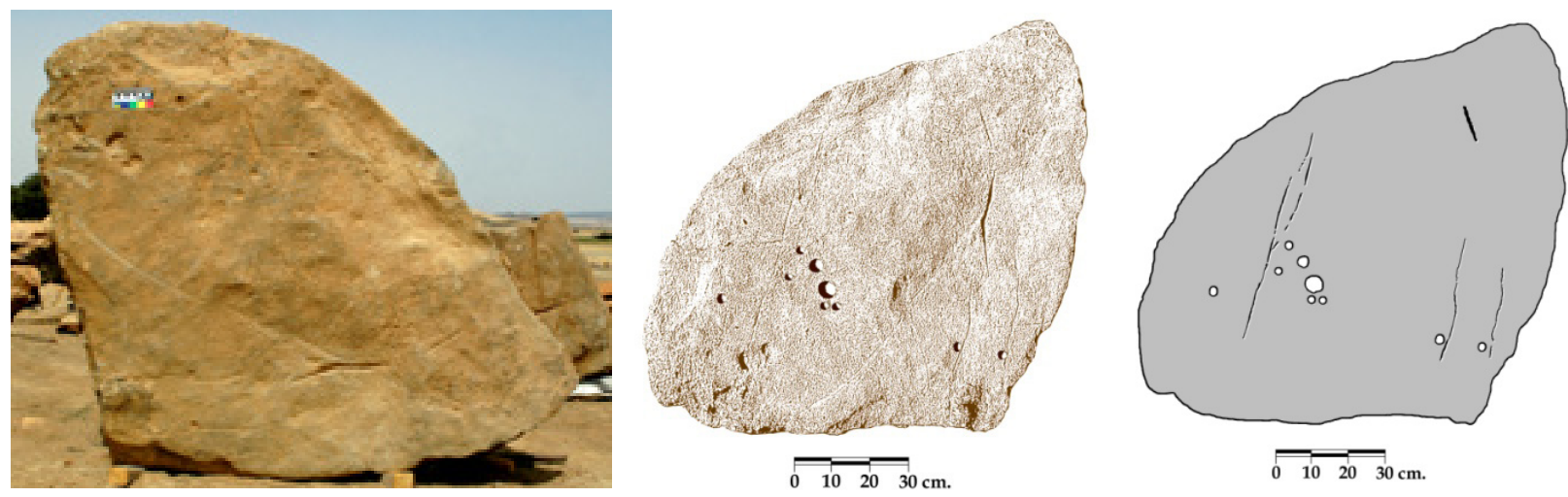

Fig. 13. Ortostato $\mathrm{n}^{\mathrm{Q}} 2$, posiblemente perteneciente al lado norte de la cámara, con cazoletas. Este ortostato se ha orientado atendiendo a la disposición del 1, in situ. 


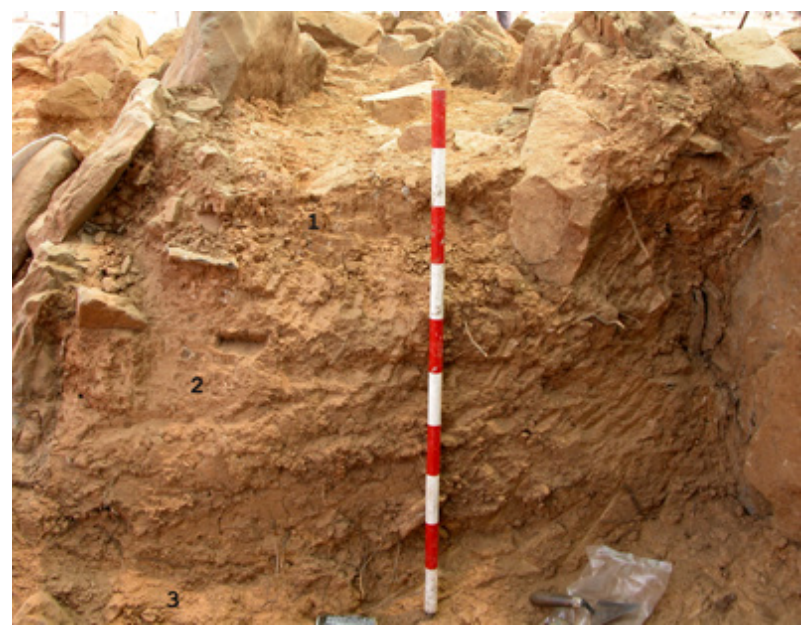

Fig. 14. Potencia estratigráfica del corredor.

inicio de ésta se erigían hacia el este una serie de bloques semejantes a los empleados en ella hasta alcanzar una distancia de 2'20 m, interrumpiéndose bruscamente la disposición de más bloques de estas características, tras los cuales aparecían algunas piedras que prolongaban el corredor en $125 \mathrm{~m}$ más, y a continuación se encontraban otras que cerraban este espacio, finalizando en una gran losa, de 1'80 $\mathrm{m}$ de longitud dispuesta transversalmente al eje del corredor, que casi apoyaba directamente en un último bloque, que comparte las características presentes -desbastado y material pétreo- en los bloques de la cámara y primer tramo del corredor, el contiguo a ésta (fig. 15).

Nivel 3: Amarillento, era el mismo que el de la base de la cámara e igualmente estéril, tratándose de un nivel de preparación sobre el que se erige la

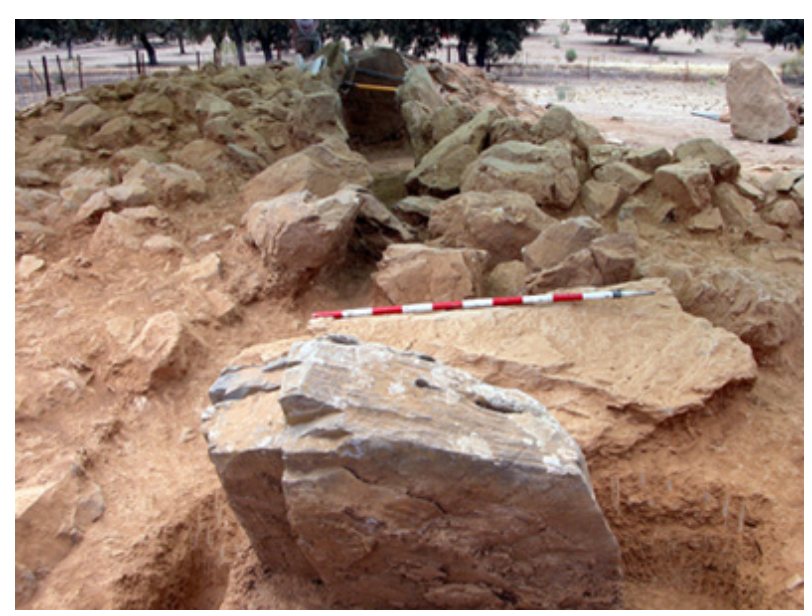

Fig. 15. Diferencia del material pétreo constitutivo del corredor y bloque de cierre. estructura funeraria. Rebajamos unos $15 \mathrm{~cm}$ con la intención de documentar las zanjas de inserción de los ortostatos, no siendo esto posible en ningún caso puesto que también aquí se habían rellenado con la misma tierra. Este nivel, de escasa potencia en algunos sectores, descansaba directamente sobre la roca madre, muy deleznable y pizarrosa.

\section{ELEMENTOS ARQUITECTÓNICOS DECORADOS}

Básicamente se observan tres tipos de grabados:

a) Líneas rectas y anchas, con una anchura media de $1 \mathrm{~cm}$, y generalmente largas (fig. 11).

b) Líneas estrechas, con una anchura media de $0,5 \mathrm{~cm}$. y de longitud variable

c) Cazoletas con tendencia circular, generalmente de pequeño diámetro, entre 1 y $4 \mathrm{~cm}$. que tienden a formar grupos (figs. 12 y 13).

Los dos primeros plantean interrogantes acerca de su categorización, dado que no conforman motivos identificables o definibles. Las cazoletas, en cambio, sí constituyen elementos gráficos conocidos del arte megalítico.

\section{III.1. DESCRIPCIÓN DE LOS MOTIVOS GRABADOS.}

Las cazoletas grabadas se presentan en las caras interiores de dos ortostatos. El ortostato al que hemos designado el $\mathrm{n}^{\mathrm{o}} 2$ fue desplazado por la retroexcavadora y formaba parte del lateral norte de la cámara, siendo el primero en el que observamos la presencia de este tipo de manifestación. El otro, $\mathrm{n}^{\mathrm{o}}$ 1 , es el segundo del corredor, situado igualmente en el lado norte. En ambos, la cara con cazoletas se dispuso hacia el interior.

\section{ORtostato 1 (FIG. 12):}

Consta de un total de 17 cazoletas de un tamaño bastante regular (en torno a $1 \mathrm{~cm}$.). Se observan dos grupos bien definidos y otras dos cazoletas separadas de ambos. El primer grupo, localizado en el tercio superior del ortostato, está formado por diez cazoletas, siendo el más numeroso. Tres de sus unidades se presentan unidas entre sí y claramente alineadas.

\section{ORTOSTATO 2 (FIG. 13):}

Registra un total de 9 cazoletas que hemos separado en dos grupos: Uno a la izquierda, en torno a la mayor cazoleta del conjunto $(4 \mathrm{~cm}$.), y una pareja a la derecha. La gran cazoleta parece haberse querido alinear con otras dos en una sucesión decreciente de mayor a menor tamaño. 


\section{III.2. VALORACIÓN DEL CONJUNTO.}

Respecto a los surcos anchos del primer tipo, pensamos que podrían ser resultado de los trabajos de desbastado de los bloques, ya que son perfectamente rectilíneos y aparecen tanto en las caras interiores como exteriores de los ortostatos. Por la forma de los surcos, en "V", pensamos que se utilizó un instrumento con filo en bisel, como hacha o azada.

Las líneas estrechas son mucho más problemáticas. Aunque su pátina las diferencia de otros surcos modernos, hecho que resulta indicativo de su mayor antigüedad, encontramos argumentos tanto a favor como en contra de que se trate de manifestaciones gráficas propiamente dichas; por otra parte, las características, grosor y limpieza de las líneas así como su recto trazado permite interpretarlas como producto de los trabajos relacionados con la extracción de los bloques y su traslado.

Por lo que respecta a las cazoletas, hay numerosos paralelos asociados no sólo en arquitecturas megalíticas, donde son muy características, sino también, aunque en menor medida, en el arte esquemático en general. Se trata de una tipología relativamente bien documentada, aunque no conocemos hipótesis sólidas en cuanto a su interpretación. Valga el ejemplo próximo del Dolmen de Viera, con decenas de estas concavidades en las caras internas de varios ortostatos del corredor.

En el caso del Dolmen de la Fuente del Corcho parece interesante la aparente disposición intencionada de algunas alineaciones, aunque éstas no constituyen aquí la pauta general. Sí se observa, en cambio, una decidida tendencia hacia el ordenamiento a partir de agrupaciones, antes que hacia la dispersión o el abigarramiento.

\section{CONSIDERACIONES FINALES}

El Dolmen de la Fuente del Corcho pertenece a los sepulcros de cámara y corredor indiferenciado, constituyendo éste una mera prolongación de los laterales norte y sur de aquella. La estructura presenta un ensanchamiento hacia el oeste que se potenció, además, por la colocación inclinada de los bloques hacia el interior -sin duda también para favorecer una cubierta más reducida- y dejarse una distancia mayor entre los bloques del lado sur y los del norte, dando cuerpo a una cámara de unos 3 $\mathrm{m}$ de oeste a este por unos 1'50 aproximadamente de norte a sur (siendo esta medida estimativa al no haberse documentado las zanjas de inserción de los ortostatos del lateral norte), mientras que el corredor, cuyos bloques se instalaron sensiblemente más verticales, cuenta con una anchura comprendida entre 1'30, en contacto con la cámara, y algo menos de $1 \mathrm{~m}$ en la zona más estrecha.

Directamente sobre la tierra virgen, muy pizarrosa y deleznable, se dispuso un suelo de preparación de tierra amarillenta y completamente estéril para acoger la estructura funeraria. En este suelo los bloques se erigieron según su altura decreciente, hecho que confiere una profundidad mayor a la cámara, 1'40, frente al corredor, cuya altura disminuye a medida que se alejan de aquella, no superando los últimos de éste los $50 \mathrm{~cm}$, muy escasa.

Sobre este nivel se encontraba una tierra roja, nivel 2, sobre la que se encontraban los escasos restos óseos recuperados y el ajuar que les acompañaba. Estaba presente en un reducido sector intacto de la cámara funeraria, donde localizamos exiguos restos de ajuar funerario y restos óseos muy fragmentados, y en el corredor. En este sector de la sepultura, y como indicamos al tratar del desarrollo de la excavación, se observaba una ligera diferencia entre el sedimento del tramo del corredor consecutivo a la cámara y el del sector más próximo a la losa dispuesta transversalmente al eje oeste-este de dicho espacio.

Atendiendo a esta disimilitud en el sedimento del nivel 2 en el corredor, y teniendo en cuenta que la mayor cantidad de restos óseos aparecían en el segundo tramo, junto con la diferencia existente entre los bloques que integran ambos tramos del corredor, que atañe tanto a la materia lítica elegida como al hecho de disponerse las piedras del segundo sin tratamiento previo, planteamos que esta estructura funeraria fue remodelada tras su utilización.

El primer tramo del corredor, en contacto con la cámara funeraria, era una mera prolongación de sus lados norte y sur, alcanzando una longitud de 2'20 m; de hecho, los bloques eran semejantes a los empleados en aquella (fig. 17 y 18), y fueron objeto del mismo tipo de tratamiento, desbastados y ligeramente suavizados. Por el contrario, a partir de la citada distancia se encontraba una serie de piedras, que no bloques, semejantes a las del túmulo sólo que de mayor tamaño, que cubrían un trayecto de $125 \mathrm{~m}$, y que asentaban directamente sobre la tierra, pero a mayor altura que las del tramo anterior (fig. 17). Tras ellas, se dispusieron otras que cierran el acceso al corredor, finalizando en una gran losa de 1'80 m de largo colocada perpendicularmente, de 


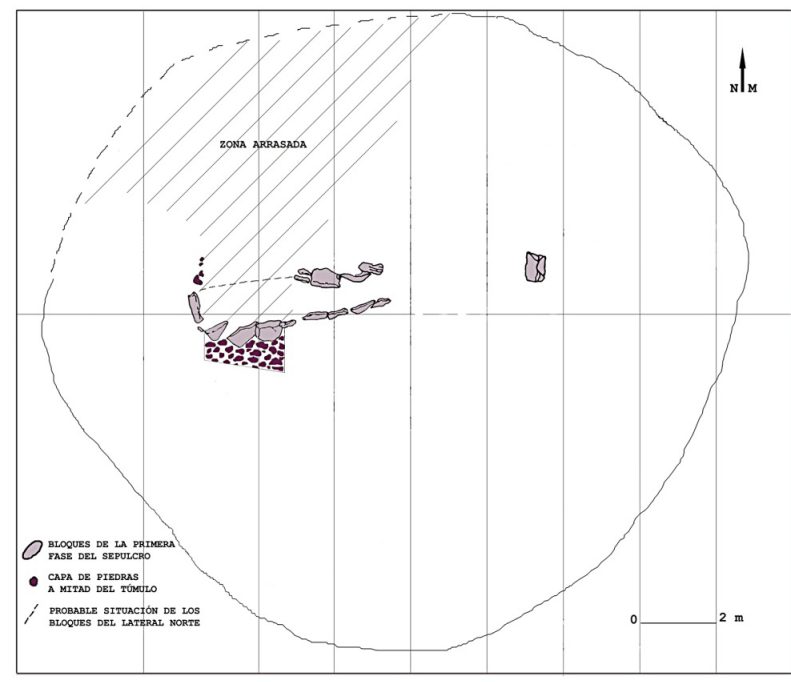

Fig. 16. Forma primigenia del Dolmen de la Fuente del Corcho.

norte a sur, a escasos $\mathrm{cm}$ del bloque final, erigido en relación al eje este-noreste. A esto hay que sumar una serie de factores: la reducida anchura del final de este tramo -hasta el punto de que algunas piedras estaban en contacto o bien dejaban un espacio pero sin comunicación con el anterior-, la escasa profundidad -una media de $30 \mathrm{~cm}$-, la ruptura de la homogeneidad -tanto simétrica como pétrea- con respecto al primer tramo y, finalmente, la desigual tonalidad que ofrecía la tierra del nivel 2.

De este modo, la forma primigenia de esta sepultura (fig. 16), homogénea y simétrica, comprendía una cámara y corredor, indiferenciado, de $520 \mathrm{~m}$ de longitud hasta los dos últimos bloques del corre-

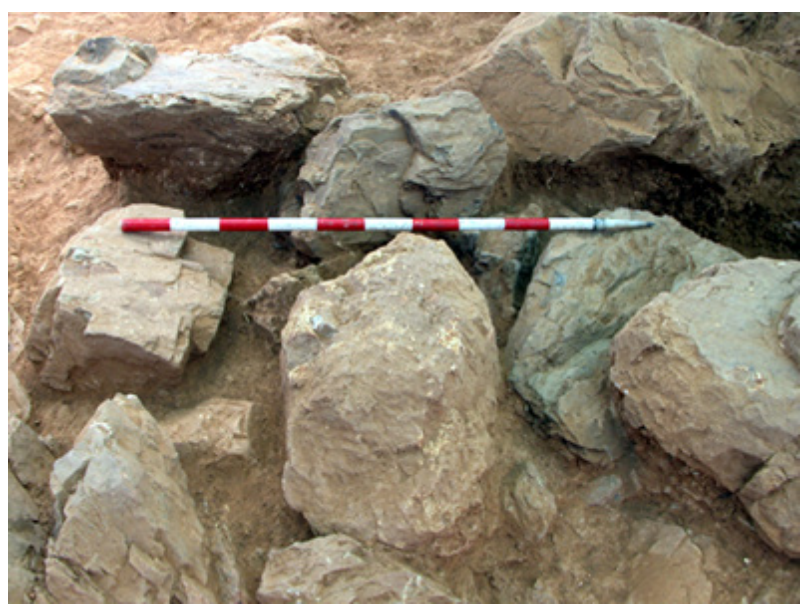

Fig. 17. Piedras del segundo tramo del corredor, colocadas directamente sobre la tierra, ya en la cota más baja del túmulo. dor conservados, y de 8'50 desde el bloque de cabecera hasta el situado en el extremo opuesto, que debió constituir un elemento señalizador, puesto que la declinación del túmulo alcanzaba escasa potencia en dirección este. Desconocemos si entre aquellos dos y éste se alinearon otros conjuntos pétreos. A partir del bloque de cabecera, la cámara se configuró añadiéndose cuatro más al sur y seguramente otros tantos al norte, uno de los cuales pudo ser el que está decorado mediante una serie de cazoletas, desplazado de su lugar original por la retroexcavadora; seguidamente se disponen los del corredor, que se inicia con dos lajas dispuestas casi en paralelo en el lateral norte (fig. 19), a continuación se encuentra el bloque con mayor número de cazoletas (fig. 12) y, tras éste, otros dos. La disposición de los ortostatos se interrumpe bruscamente en dirección este, encontrándose, en dicho lado antes del primer bloque, una capa de piedras de reducido tamaño ocasionadas por un derrumbe y/o remodelación, y sobre éstas las del túmulo (fig. 18).

Al exterior, a media altura de los bloques, se colocó una capa de piedras que, al menos, debía rodear la cámara funeraria (figs. 8 y 20), cubriéndose la estructura resultante mediante el túmulo de tierra. Los bloques que forman esta primera fase son homogéneos en lo que se refiere a la materia elegida y al tratamiento de desbastado y regularizado, siendo dos de los correspondientes a esta primigenia arquitectura los que presentan cazoletas y trazos.

Tras la deposición de los cadáveres, el dolmen es objeto de saqueo. Si bien no resulta factible precisar cuánto tiempo transcurrió entre aquella y el expolio, esta acción conllevó la remoción y desplazamiento de aquellos de su lugar original, al menos en parte. Desconocemos, por el alto grado de fragmentación de los restos óseos localizados, si las inhumaciones fueron de primer o segundo grado, pero quizá no resulte descabellado inclinarse a favor de inhumaciones secundarias a juzgar por el reducido tamaño de los escasos restos óseos, hecho que favorecería su fragmentación y dispersión durante la violación, siendo desplazados hacia los bloques del corredor y, en el caso de los localizados en la reducida zona intacta de la cámara, hacia los del lado sur.

En buena lógica cabe suponer que este acto de violación fue el factor causal de la ligera diferencia entre el sedimento del nivel 2 en ambos tramos del corredor, de la disimilitud existente entre los bloques del primer tramo de éste con respecto a 
las piedras del segundo y del derrumbe de piedras, comportando el saqueo el destrozo del acceso al interior, que se reestructura añadiendo piedras irregulares y sin tratamiento posterior a su extracción hasta enlazar con el bloque final, el dispuesto en eje con el corredor y el bloque de cabecera de la cámara.

Estas piedras se colocaron directamente sobre la tierra (fig. 17), confirmando este hecho que la remodelación se llevó a cabo tras el desvalijamiento. De este modo, en el lateral norte se depositaron tres piedras y cuatro en el sur, cubriendo una distancia de 1'25 m hasta finalizar en una situada en el centro, tras la cual se dispusieron otras también en el centro que cierran el acceso al interior de la sepultura, así como la gran losa de 1'80 de longitud, dispuesta transversalmente al eje del corredor y que clausura el acceso al interior, ya casi a ras de la base del túmulo (fig. 15). De este modo, la estructura, en parte desmantelada, se completa y clausura hasta el bloque de señalización (figs. 15 y 16).

Siguiendo con el criterio de la diferente elección del tipo de materia pétrea, nos plantemos si no resulta lógico atribuir a esta "remodelación" las piedras que cubren buena parte del túmulo, puesto que son más abundantes hacia el este.

Hasta ahora, nada hemos mencionado acerca del sistema de cubrición de la cámara y el corredor. Al respecto, hemos de hacer notar que, a pie de excavación, consideramos la posibilidad de que uno o más de los bloques desplazados al interior de la cámara pudiesen formar parte de la cubierta de este espacio, sin embargo, teniendo en cuenta que su número se corresponde con los del lado sur, opinamos que deben constituir el norte, a lo que hay que sumar que, aunque los bloques in situ que forman este espacio se colocaron inclinados para acortar la distancia superior y permitir una cubierta mediante una o más losas de dimensiones más reducidas, sus longitudes no resultan suficientes para tal finalidad. Por su parte, y asimismo, las piedras sueltas que se encontraban encima o próxima a la zona del corredor tampoco resultaban adecuadas para formar la cubierta de este sector, ya que no alcanzan la longitud necesaria para apoyar en los bloques de ambos lados.

De este modo, y teniendo en cuenta lo anterior, opinamos que la cubierta de esta sepultura fue desmantelada hace tiempo. Al respecto debe tenerse en cuenta que el corredor, no afectado por el expolio clandestino reciente, no ofrecía cubrición de ninguna clase, presentando en toda la potencia del nivel
1 y los primeros $20 \mathrm{~cm}$ del 2 piedras de mediano tamaño, entre $20-30 \mathrm{~cm}$ y de las mismas características que las del túmulo, continuando éstas hasta la mitad del citado nivel y que difícilmente se hubieran podido filtrar por los intersticios dejados entre un bloque y otro de la cubrición pétrea de este sector. Ante esto cabe pensar que la cubierta de este espacio pudo ser desmantelada si no en época prehistórica, al menos hace bastante tiempo ya que en las cercanías del dolmen sólo pudimos localizar un bloque, de características similares a los del segundo tramo del corredor, que hubiera podido formar parte de la cubierta. Pensar en un sistema de cubierta a base de materiales orgánicos no resulta acertado desde nuestro punto de vista porque no hubieran soportado el peso de la tierra y las piedras del túmulo, desplomándose pasado un tiempo y dejando, por tanto, evidencias en el sedimento, no observadas en ningún momento.

Finalmente, en cuanto al uso de la sepultura megalítica, el ajuar resulta excesivamente parco para precisar la cronología, pero las puntas de flecha, de base cóncava, remiten a la plenitud del Calcolítico si atendemos a la estratigrafía de Sierra Palacios I, en la que dominan este tipo de foliáceos, y a cuya necrópolis dolménica pertenece este dolmen. Por otra parte, y por las mismas razones, no resulta factible plantear un dilatado tiempo de utilización de la sepultura, no apreciándose en el nivel 2 ningún tipo de evidencia que plasmase una segunda etapa de deposición de cadáveres tras el saqueo del ajuar y remoción de los restos óseos humanos, de manera que ocurrida la violación el dolmen fue objeto de

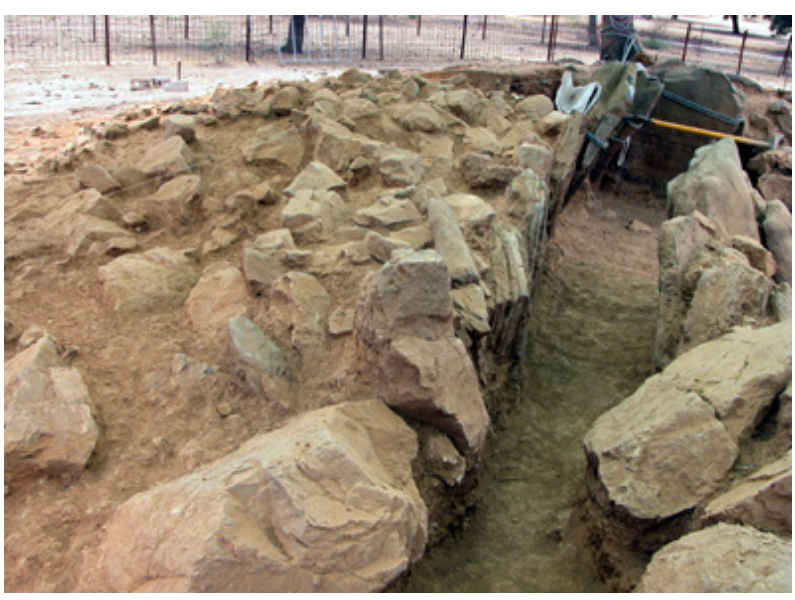

Fig. 18. Los dos tramos del corredor. Obsérvese la diferencia en el material pétreo empleado, y la costra de piedras que cubre el túmulo. 
remodelación y cierre definitivo, clausurándose el interior de este espacio funerario, que volverá a acoger un enterramiento hacia finales del III milenio y comienzos del II, de cuya evidencia ha quedado un cuenco y un fragmento de cerámica campaniforme, manifestando de este modo una continuidad, si no en el rito -individual o colectivo- sí en el espacio elegido, denotando este hecho que estas arquitecturas siguen teniendo un significado simbólico importante en el seno de estas sociedades, de manera que aunque se acojan al nuevo ritual individual, el cadáver se deposita en el mismo espacio funerario que el de los antepasados, revalidándose así, como indican algunos autores (Bueno et alii, 1999), la continuidad en el derecho a la posesión, uso y control del territorio.

Si bien, como hemos indicado más arriba, al haber sido expoliado tanto en momentos prehistóricos como actuales, el ajuar recuperado no permite una definición arqueológica precisa, sí que podemos apuntar que una comparación con el procedente del de Casas de Don Pedro remite a un momento posterior en el uso del Dolmen de la Fuente del

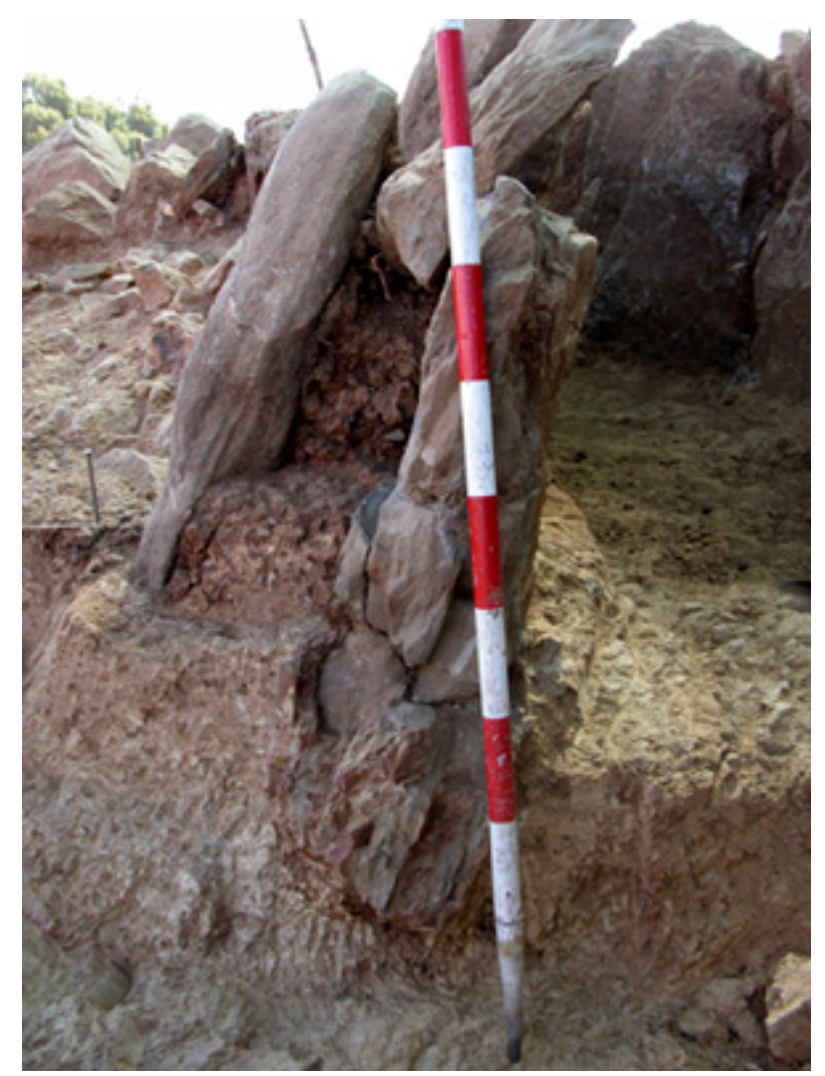

Fig. 19. Losas en paralelo que indican el comienzo del corredor.
Corcho. Por otra parte, este difiere también con respecto a aquel en el tamaño de los ortostatos empleados, siendo los de éste sensiblemente menores, hecho que resta monumentalidad a este sepulcro. Pese a ello, cuenta con dos bloques decorados mediante cazoletas, ausentes en el primero. Aunque la disposición que presentan las cazoletas de ambos ortostatos está siendo analizada desde una óptica arqueoastronómica, cuyo resultado es objeto de un trabajo en curso de realización, queremos señalar que la distribución que presentan algunas de ellas, sobre todo en el ortostato $\mathrm{n}^{\mathrm{o}} 1$, permite plantear su posible relación con la constelación de Orión, como se ha hecho en el caso de otras estructuras megalíticas, caso del círculo de la Pasada del Abad, aunque con otras constelaciones (Vera et alii, 2010).

Por último, en cuanto a su situación, cabe destacar que se encuentra muy próximo a la cabecera de dos arroyos que, discurriendo hacia el norte, desembocan en el Fresnedoso uno y en el Guadiato el otro, y constituyen una vía natural de comunicación entre la zona sur y suroeste, más montañosa, y la norte, notoriamente más llana y sobre la que se distribuyen otros sepulcros megalíticos pertenecientes a la necrópolis de Sierra Palacios I (fig. 2), como los de Sierra Palacios IV y V, hasta alcanzar el Dolmen de las Casas de Don Pedro y el de Sánchez Pastor, situados, el primero, en la margen derecha del Fresnedoso y, el segundo, en la izquierda; ambos dólmenes, perfectamente visibles el uno desde el otro, están ejerciendo un control sobre el Fresnedoso y sobre el acceso hacia el Guadiato. Como hemos planteado en otro trabajo (Gavilán, 2003-2004), esta necrópolis, al igual que otras de la zona, se distribuye por la margen derecha del Guadiato, excepción hecha del Dolmen de Cabeza de Vaca (fig.2), mientras que los poblados se localizan en cerros aislados situados en la margen izquierda del mismo curso fluvial.

Así, pues, el Dolmen de la Fuente del Corcho, por su ubicación, pudo actuar como elemento simbolizador de posesión territorial, función que se vería reforzada al ser construido sobre un cerro que, aunque de escasa altura, domina una amplia panorámica hacia el sur, en dirección a Sierra Palacios (Mapa 1), al tiempo que el túmulo fue provisto de una capa de piedras de mediano tamaño que debió contribuir a su visualización desde cierta distancia y desde antes de acceder hacia la zona llana que acaba, con una ligera caída, en el Fresnedoso y el Guadiato, sobre el que se encuentra el poblado de Sierra Palacios, que 
constituyen vías naturales de comunicación, siendo la del Guadiato la más importante del sector noroccidental de la provincia de Córdoba. En definitiva este sepulcro, junto con los restantes de esta necrópolis están ejerciendo un control desde las zonas más cerradas de sierra hasta el poblado de Sierra Palacios.

\section{CATÁlogo de materiales.}

Evidentemente, al tratarse de un dolmen expoliado tanto en época prehistórica como actual, los exiguos restos materiales se encontraban desplazados de su lugar original de deposición. A esto obedece, sin duda, el hecho de que la mayor parte del ajuar recuperado corresponda a fragmentos cerámicos, siendo las industrias líticas y ornamentales francamente escasas, no descartándose la posibilidad de que los cadáveres estuviesen acompañados por otros elementos menos usuales y directamente relacionados con el prestigio.

\section{V.1. TÚMULO:}

Cerámica (fig. 7):

$\mathrm{N}^{\mathrm{o}}$ 4: Fragmento de cerámica campaniforme impreso e inciso. Buena calidad exterior e interior; cocción reductora, desgrasante fino, color negruzco al exterior y marrón al interior.

№ 5: Cuenco completo. Buena calidad exterior e interior; cocción reductora; desgrasante fino, color marrón en ambas caras.

№ 6: Fragmento de vasija ligeramente carenada. Buena calidad en ambas caras. Cocción alternante; desgrasante medio, color marrón. Presenta una capa de almagra en la cara interna.

$\mathrm{N}^{\mathrm{o}}$ 26: Fragmento de borde, redondeado de dirección y diámetro no determinables. Baja calidad; cocción alternante; desgrasante grueso y de tonalidad negruzca.

$\mathrm{N}^{\mathrm{o}}$ 28: Fragmento de borde, labio indicado, de dirección y diámetro no determinables. Buena calidad; cocción reductora; desgrasante medio. Color negruzco.

№ 21: Fragmento de asa de cinta. Buena calidad, cocción alternante, desgrasante grueso, color marrón en ambas caras.

№ 33: Fragmento de cuernecillo.

19 fragmentos atípicos sin decoración.

Industria lítica tallada (fig. 21):

$\mathrm{N}^{\mathrm{o}}$ 1: Lasca laminar, completa, bulbo extraído, sin talón. Retoque abrupto directo derecho, abrupto inverso izquierdo. 32/15/6. Sílex gris.

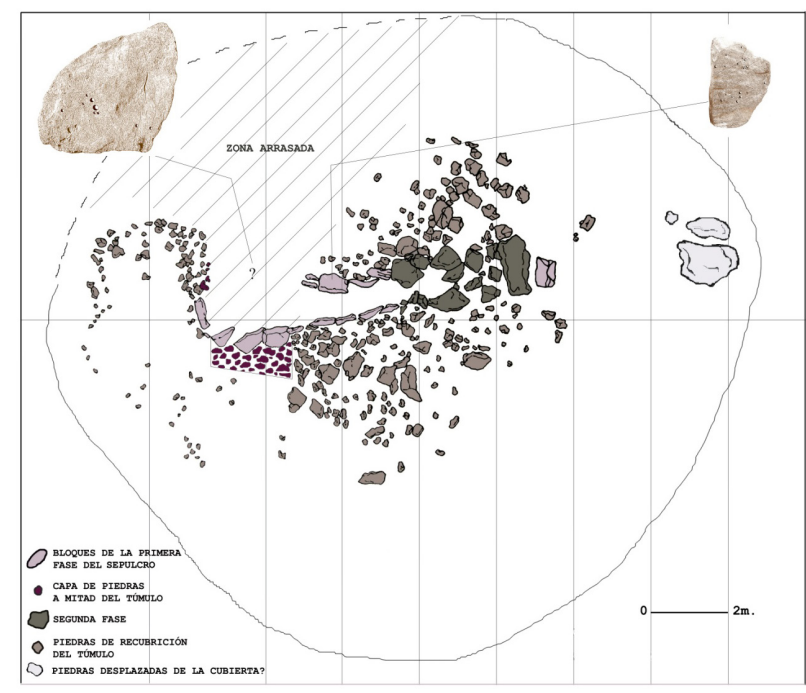

Fig. 20. Planta final. Se señalan las distintas fases constructivas.

№ 2: Truncadura sobre fragmento de hoja. $\mathrm{mm}$. Retoque abrupto inverso derecho. 72/21/4. Sílex crema.

$\mathrm{N}^{\circ}$ 3: Lasca. Retoque semiabrupto directo izquierdo. 34/25/4 mm. Sílex cuarzoso.

Materiales recuperados en las inmediaciones del túmulo:

- Azada.

- Fragmento de cuarcita con talla y evidencias de haber sido utilizada como percutor.

\section{V.2. CÁMARA:}

\section{Cerámica:}

№ 3-4 (fig. 22): Fragmentos de cuenco. Borde redondeado, recto, diámetro $14 ' 8 \mathrm{~cm}$. Buena calidad exterior e interior; cocción alternante, desgrasante grueso; color marrón en ambas caras.

№ 1,2 y 6 (fig. 22). Tres fragmentos de cuenco hemisférico. Borde redondeado, recto, $13^{\prime} 4 \mathrm{~cm}$. de diámetro. Buena Calidad; cocción oxidante; desgrasante medio: Color rojizo.

№ 7-8: fragmento de asa, no determinable.

№ 11: Fragmento de borde, redondeado, saliente, diámetro no determinable. Buena calidad exterior e interior; nervio de cocción, desgrasante medio, color marrón en ambas caras.

№ 19, 21 y 25 (fig. 22): Tres fragmentos de una misma cazuela carenada. Buena calidad exterior e interior; cocción reductora, desgrasante muy grueso, color rojizo exterior y beige al interior.

11 fragmentos atípicos sin decorar, uno de ellos a torno. 

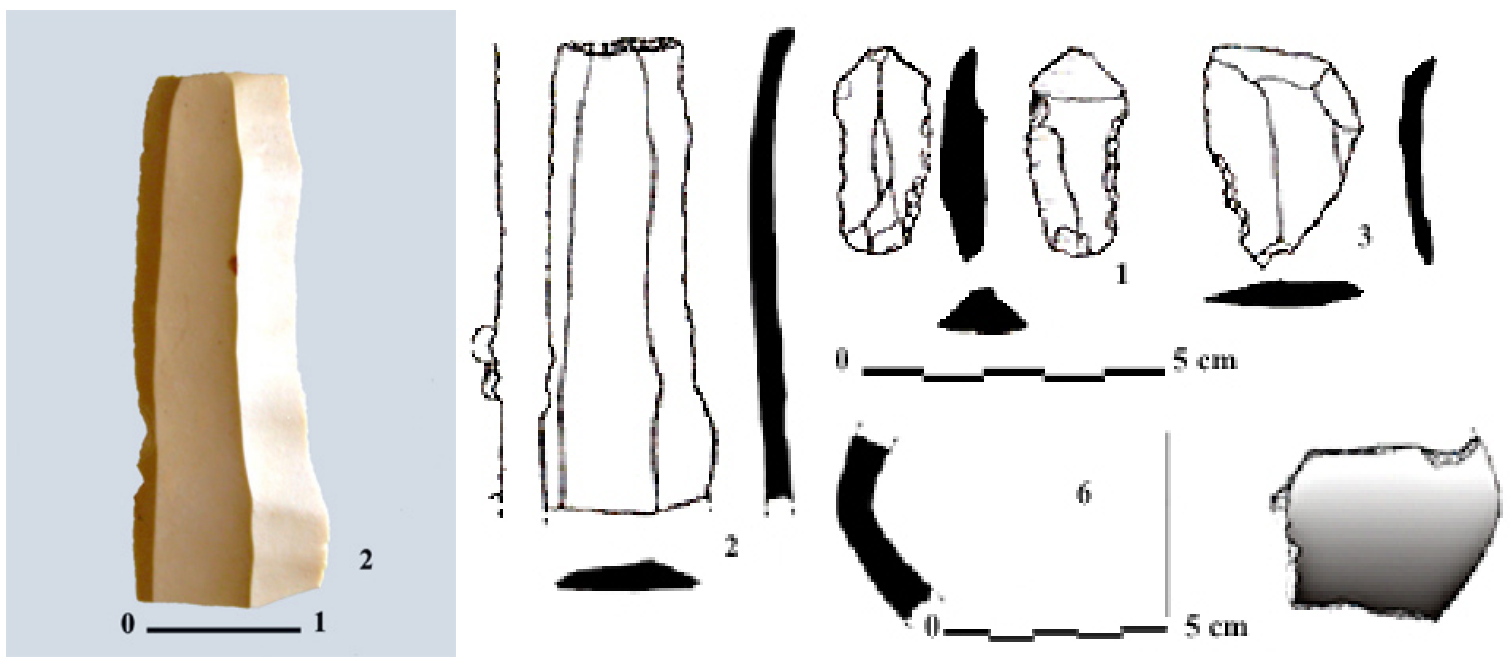

Fig. 21. Restos procedentes del túmulo.

\section{Industria lítica tallada:}

№ 17: Fragmento de hoja, sin retoque, córtex III. 19/11/2 mms. Sílex beige grisáceo.

№ 16: Fragmento de núcleo, extracción de láminas. Sílex gris.

№ 24 (fig. 22): Fragmento de punta de flecha; 12/9/3 mms. Cuarzo blanco.

№ 28 (fig. 22): Punta de flecha. 25/18/4 mm. Sílex negro local.

Piedra pulimentada:

№ 30 (fig. 22): Hacha pulimentada, conserva restos de piqueteado. 9'2/4'2/1'8 cms.

Piedra exógena:

№ 31: Fragmento de piedra, sin señales de manipulación. Cabe destacar que en las inmediaciones del Pantano de Sierra Boyera comprobamos la existencia de piedras semejantes, y que tenemos dudas acerca de esta pieza, ya que al estar la cámara expoliada pudo llegar hasta allí por múltiples causas.

\section{V.3. CORREDOR}

\section{Cerámica:}

№ 80 (fig. 23): Cocción reductora; desgrasante medio; color gris; grosor $5 \mathrm{~mm}$.

№ 81 (fig. 23): Cuenco, cocción reductora, desgrasante medio, color gris, grosor $4 \mathrm{~mm}$.

$\mathrm{N}^{\mathrm{o}} 51$ (fig. 24): Fragmento de cuenco, borde re-
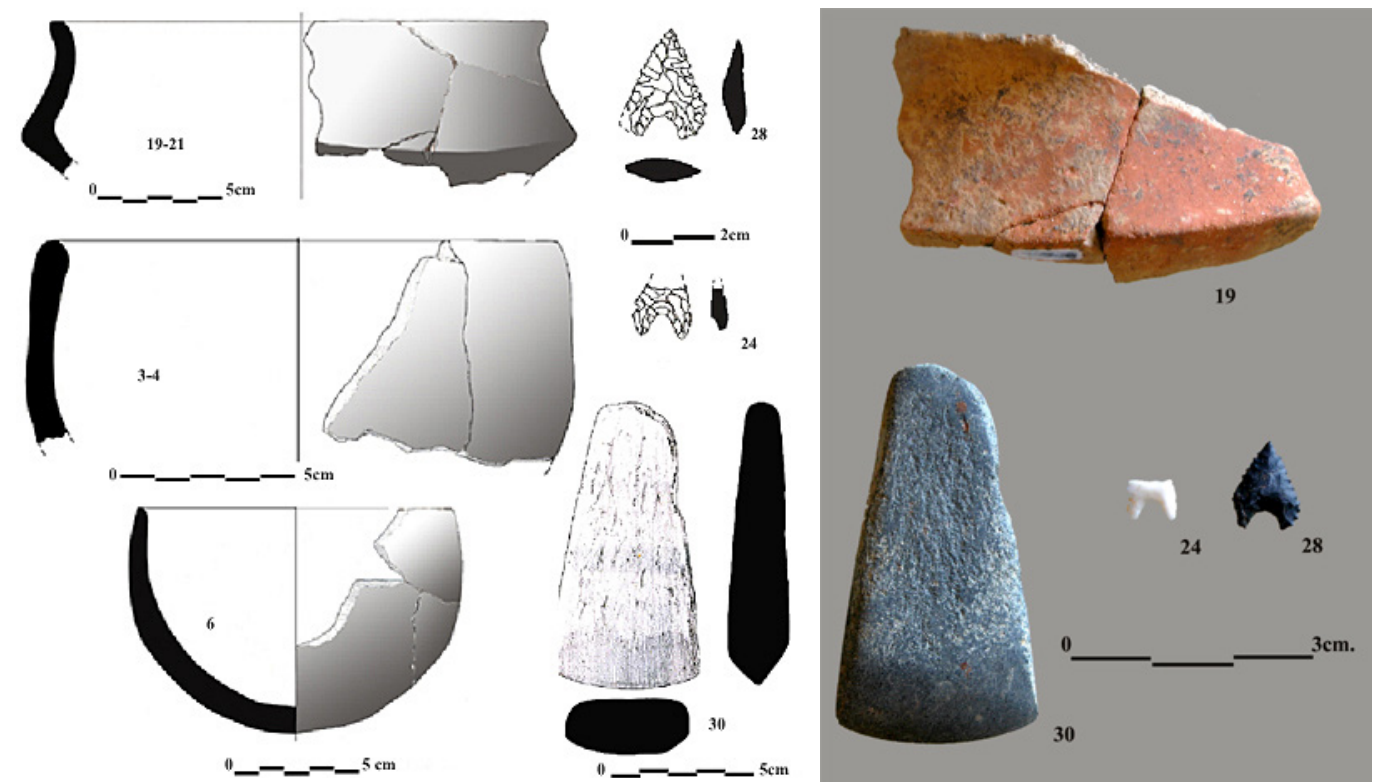

Fig. 22. Ajuar procedente del interior de la cámara. 


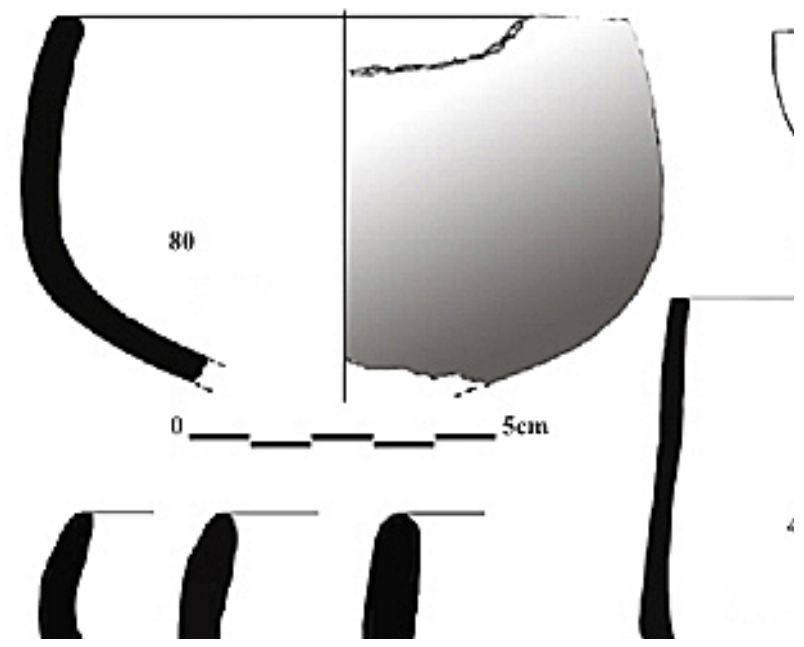

Fig. 23. Ajuar recuperado en el corredor.

dondeado, saliente, de $25 \mathrm{~cm}$. De diámetro. Buena calidad en ambas caras, cocción oxidante; desgrasante fino, color marrón.

№ 43 (fig. 23): Varios fragmentos pertenecientes a la misma vasija. Borde semiplano, ligeramente entrante, de $19 \mathrm{~cm}$. De diámetro. Buena calidad exterior e interior, cocción oxidante, desgrasante grueso, color marrón en ambas caras.

№ 40 (fig. 24): Fragmento de plato de borde engrosado. $26 \mathrm{~cm}$ de diámetro. Buena calidad exterior e interior; cocción oxidante, desgrasante muy grueso, color rojizo.

$\mathrm{N}^{\mathrm{o}} 53$ (fig. 23): Fragmento de borde, redondeado, de dirección y diámetro ignorados. Buena calidad exterior e interior, cocción alternante y desgra-
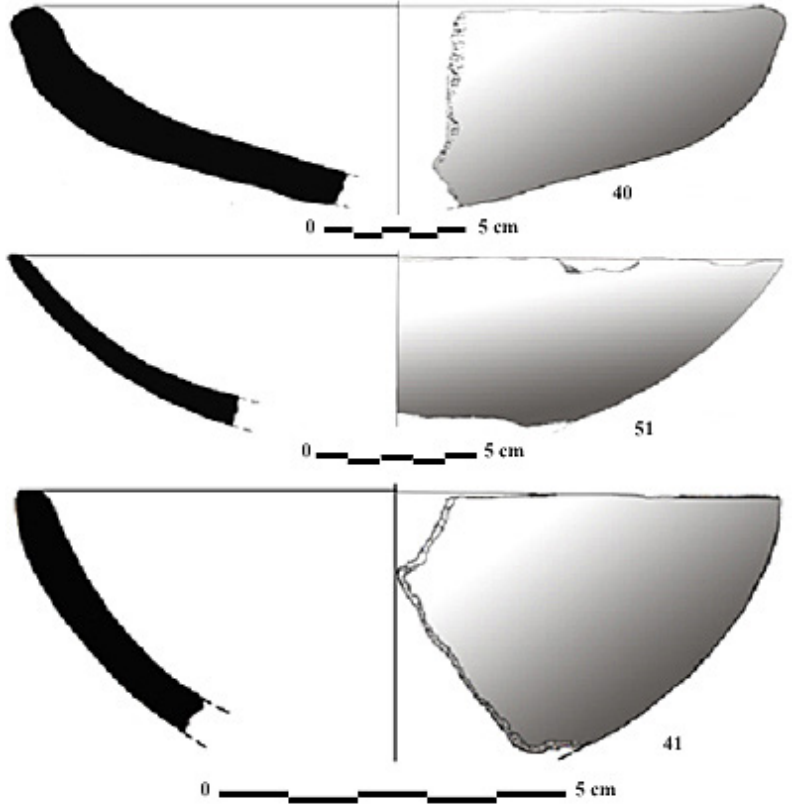

Fig. 24. Ajuar procedente del corredor. Cuencos.

sante grueso. Color marrón al exterior y negruzco al interior.

№ 47 (fig.23): Fragmento de borde, redondeado, entrante, de diámetro no determinable. Baja calidad exterior e interior, cocción alternante, desgrasante fino, color rojizo.

№ 62 (Fig. 21): Fragmento de borde, apuntado, entrante, diámetro no determinable. Baja calidad en ambas caras, cocción oxidante, desgrasante medio, color marrón exterior e interiormente.
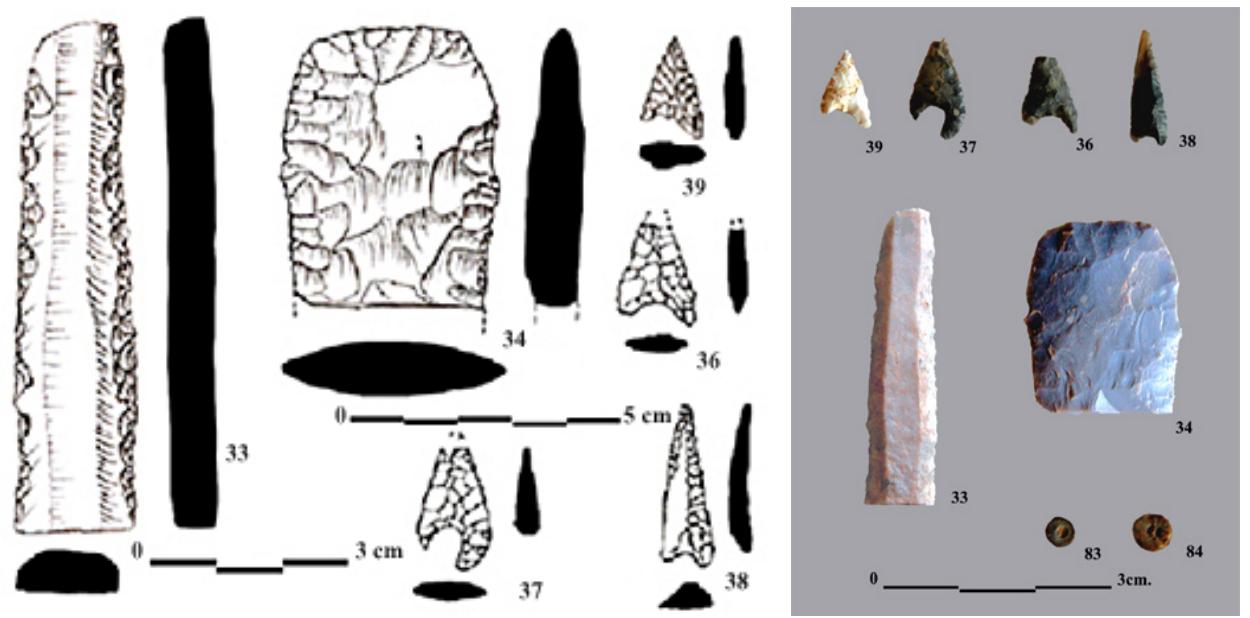

Fig. 25. Corredor, industria lítica tallada y ornamental. 
№ 52 (fig. 23): Varios fragmentos pertenecientes a la misma vasija. Borde, redondeado, entrante, de $18^{\prime} 6 \mathrm{~cm}$. De diámetro. Presenta un mamelón elíptico macizo. Buena calidad exterior e interior, cocción reductora, desgrasante muy grueso, color negruzco en ambas caras.

№ 41 (fig. 24): Fragmento de cuenco, borde redondeado, saliente, de $12 \mathrm{~cm}$. De diámetro. Buena calidad en ambas caras, cocción oxidante, desgrasante medio, color negruzco.

№ 102: Fragmento de cuernecillo.

38 fragmentos atípicos sin decorar.

Industria lítica tallada:

№ 33 (fig. 25): Fragmento de hoja, sin talón ni bulbo. Retoque abrupto directo bilateral. 79/19/6 $\mathrm{mm}$. Sílex beige.

№ 34 (fig. 25): Fragmento de lámina. Retoque laminar directo e inverso. 55/46/10 mms.; sílex gris.

№ 35: Lasca completa, talón cortical y bulbo.31/22/3'5 mms. Sílex gris.

№ 36 (fig. 25): Fragmento de punta de flecha. 20/14/3 mms. Sílex gris oscuro.

№ 37 (fig. 25): Punta de flecha. 27/14/3. Sílex gris oscuro.

№ 38 (Fig. 23): Punta de flecha. 33/9/5’5. Sílex gris oscuro.

№ 39 (fig. 25): Punta de flecha. 20/11/3. Sílex blanco.

\section{Adorno:}

№ 83 (fig. 25): Cuenta de collar.

№ 84 (fig. 25): Cuenta de collar.

Bibliografía

Bueno, P., Balbín, R., de, Barroso, R., Alcolea, J.J., Villa, A. y Moraleda, A. (1999), El Dolmen de Navalcán. El poblamiento megalítico en el Guadyerbas, Toledo.

Gavilán, B. (2003-2004), "El Alto Valle del Guadiato durante la Prehistoria reciente: el poblamiento Neolítico y Calcolítico", Espacio, Tiempo y Forma, Serie I, Prehistoria y Arqueología, 16-17, 119-160.

Gavilán, B. y Vera, J.C. (2005), "Neolítico y megalitismo prefunerario en Andalucía," III Congreso del Neolítico en la Península Ibérica (P. Arias, R. Ontañón, y C. García-Moncó, Eds.), Monografías del Instituto Internacional de Investigaciones Prehistóricas de Cantabria, 1, 535-
541.

Vera, J.C., Linares, J.A., Martín, D., Camalich, M ․D., y González, P. (2010), "Los inicios de la producción de alimentos en Huelva. Pasado y presente”, En Os últimos caçadores-recolectores e as primeiras comunidades productoras do sul da Península Ibérica e do norte de Marrocos (J.F. Gibaja y A.F. Carvalho, Eds.), Promontoria Monográfica, 15, 119-129. 